\title{
Design of Ship Course Controller Based on Fuzzy - PID Algorithm
}

\author{
Mengqiang $\mathrm{An}^{1, \mathrm{a}}$, Peng Zhou ${ }^{2, \mathrm{~b}}$ and ZhongXing Zheng ${ }^{3, \mathrm{c}}$ \\ ${ }^{1}$ School of Automation, Wuhan University of Technology \\ Wuhan,430070, People's Republic of China. \\ Email:a1437181095@qq.com, ${ }^{\mathrm{b}} 2020650040 @ q q . c o m$
}

Keywords: ship course controller, control rules of fuzzy-PID , control system of steering engine

\begin{abstract}
In order to meet the high-performance and self-adaption requirements of ship course control at present, fuzzy - PID control design is adopted for the ship course control system in this paper. Such control design has attracted various advantages of PID control, so the complex nonlinear system of ship steering engine is linearized and the complexity of control system is improved.[1] Fuzzy control can optimize PID control parameters and increase the ability of ship control system to adapt to the environment, especially the adaptability to unknown, nonlinear and complex objects of mathematical model. [2]It can be observed through simulation that this controller possesses strong robustness for nonlinearity of ship navigation, parameter uncertainty, environmental uncertainty and variation of control object model.
\end{abstract}

\section{Introduction}

With the continuous development of society and economy,the seaborne trade all over the world become more and more frequently.Nowadays,the traditional steering controllers can't satisfy human's demand for the accurate angle of steering engine,because of low accurate,slow speed,the signal distortion and the unbalanced transmission structure.However,the fuzzy-PID algorithm can deal with the problems,and add up a number of advantages for the steering engine controlled.It's realizing the convenient control to ships.

\section{Main body}

Control system structure. A typical ship course control system mainly changes the ship course by relying on the steering engine, so as to make the ship turn to or approach the target position. Design of this controller not only aims to solve basic steering problems of steering engine but also tries to overcome the influence of various interference factors. In this way, accurate and stable ship turning will be realized.

Ship course controller is mainly composed of seven parts which are input and output units, A/D and D/A conversion units, fuzzy parameter correction unit, PID regulating unit, PWM signal output unit, motor driving unit, and position, velocity and rudder deflection angle feedback unit. [3]By combining the above seven units, the schematic diagram shown in Fig.1 can be gained.

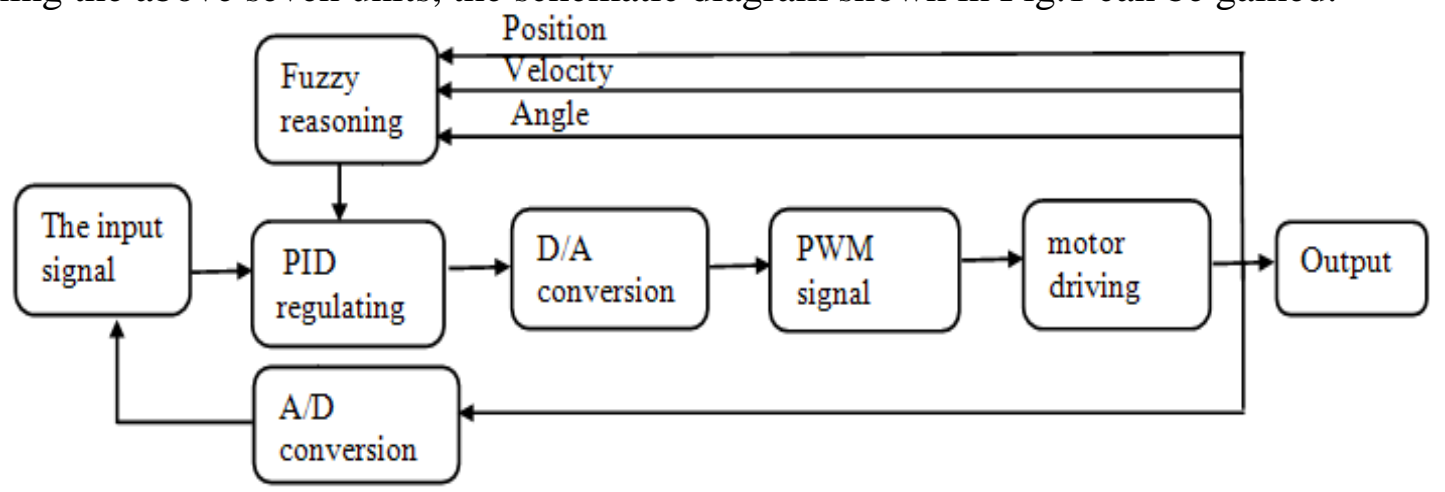

Fig.1 Structure diagram of ship course controller 
Mathematical description of the control system.In order to establish the mathematical model of the direct-current motor,make system analysis simple and facilitate the analysis, suppose that the motor meets the following conditions:

1. The magnetic circuit is unsaturated, the influences of magnetic hysteresis and eddy-current loss are ignored, and the influence of magnetic potential outside the space is neglected.

2. All magnetic potentials of excitation land in the air gap.

3. The influence of armature reaction is ignored.

The electromagnetic torque equation is: $\mathrm{m}_{\mathrm{m}}(t)=\mathrm{C}_{\mathrm{m}} \mathbf{i}_{\mathrm{a}}(\mathrm{t})$

The counter electromotive force of armature: $\mathrm{e}_{a}(t)=C_{e} \omega_{m}(t)=C_{e} * d \theta_{m}(t) / d t$

The loop voltage balance equation of armature: $U_{\mathrm{a}}(t)=L_{a} * d i_{a}(t) / d t+R_{a} * i_{a}(t)+e_{a}(t)$

The torque balance equation on motor reel: $m_{m}(t)=m_{c}(t)+f_{m} * d \theta_{m}(t) / d t+J_{m} * d^{2} \theta_{m}(t) / d t^{2}$

Generally speaking, the armature inductance La is very small, so it can be ignored. The following formula is gained after eliminating intermediate variables $\mathrm{m}_{\mathrm{m}}(\mathrm{t}), i_{a}(\mathrm{t})$ and $\mathrm{e}_{\mathrm{a}}(\mathrm{t})$ :

$J_{\mathrm{m}} R_{a} * d^{2} \theta_{m}(t) / d t^{2}+\left(f_{m} R_{a}+C_{m} C_{e}\right) d \theta_{m}(t) / \mathrm{d} t=C_{m} u_{a}-R_{a} m_{c}$

So $T_{\mathrm{m}} * d^{2} \theta_{m}(t) / d t^{2}+d \theta_{m}(t) / d t=K_{m} u_{a}-K_{n} m_{c}$

For $T_{m}=J_{m} R_{a} /\left(f_{m} R_{a}+C_{m} C_{e}\right) \quad K_{\mathrm{m}}=C_{m} /\left(f_{m} R_{a}+C_{m} C_{e}\right) \quad K_{\mathrm{n}}=R_{a} /\left(f_{m} R_{a}+C_{m} C_{e}\right)$

When $m_{c}=0$, the dynamic equation can be gained: $T_{m} * d^{2} \theta_{m}(t) / d t^{2}+d \theta_{m} / d t=K_{m} u_{a}$

In the formula, $u_{a}$ means the voltage input quantity; $\theta_{\mathrm{m}}$ refers to the rotating angle output quantity of direct-current motor; La indicates the armature inductance; $\mathrm{R}_{\mathrm{a}}$ denotes the armature resistance; $i_{a}(t)$ signifies the armature current; $m_{m}(t)$ represents the electromagnetic torque; $\mathrm{e}_{\mathrm{a}}(\mathrm{t})$ means the counter electromotive force of armature; $J_{m}$ is the rotational inertia of armature; $f_{m}$ refers to the viscous friction coefficient on motor reel; $m_{c}$ indicates the load torque.

We can gained transfer function of direct-current motor:

$u_{a}(t)$ means the voltage input quantity; $\theta_{m}(t)$ refers to the output quantity; the derivative equation is given by the above. Laplace transformation is conducted and the transfer function is:

$$
G(s)=\theta_{m}(S) / u_{a}(s)=K_{m} * 1 / s * 1 /\left(T_{m} s+1\right)
$$

Thus second-order system model is established for the driving unit.

Design idea and algorithm realization of fuzzy - PID self-tuning.Self-tuning fuzzy - PID control sets deviation $\mathrm{E}$ and deviation change rate EC as input, which can satisfy the requirements of deviation E and deviation change rate EC for PID parameter self-tuning at different times. [4]By applying fuzzy theory to correct PID parameters, self-tuning fuzzy - PID control unit is formed. The design idea of PID parameter self-tuning is to find out the relation between three PID parameters and deviation $|E|$ \& deviation change rate $|E C|$. During work, parameters $K_{P}, K_{I}$ and $K_{D}$ are corrected according to fuzzy control principle by continuously detecting $|\mathrm{E}|$ and $|\mathrm{EC}|$, so as to meet different requirements of $|\mathrm{E}|$ and $|\mathrm{EC}|$ for control parameters. The structure chart of fuzzy - PID control algorithm is presented in Fig.2 


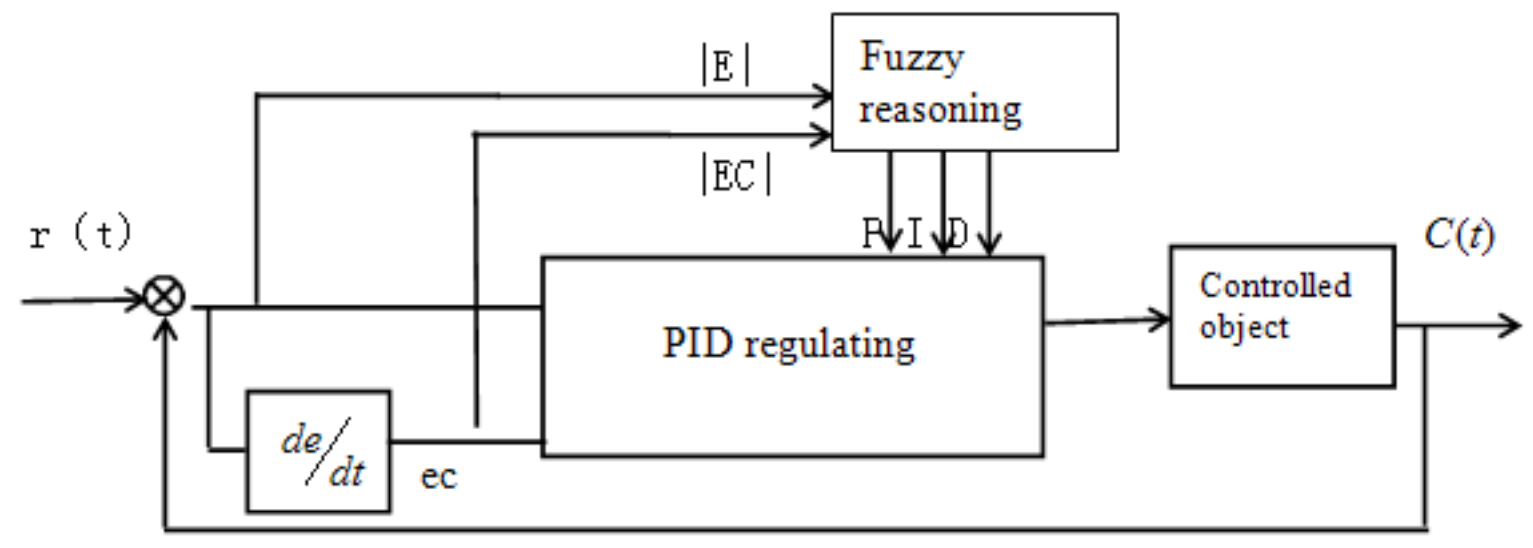

Fig. 2 Structure chart of fuzzy - PID control algorithm

Language variables of deviation, deviation change rate and control variable output are set, and the following 7 language variables are adopted for description: "positive big (PB)", "positive moderate (PM)”, “positive small (PS)”, "zero (Z)”, "negative small (NS)”, "negative moderate (NM)”, and "negative big (NB)". The field of every variable is $\{-6,-5,-4, \ldots 0,+1, \ldots+6\}$. In order to better linearize the system, triangular membership function is adopted. The membership function is shown in the following figure.

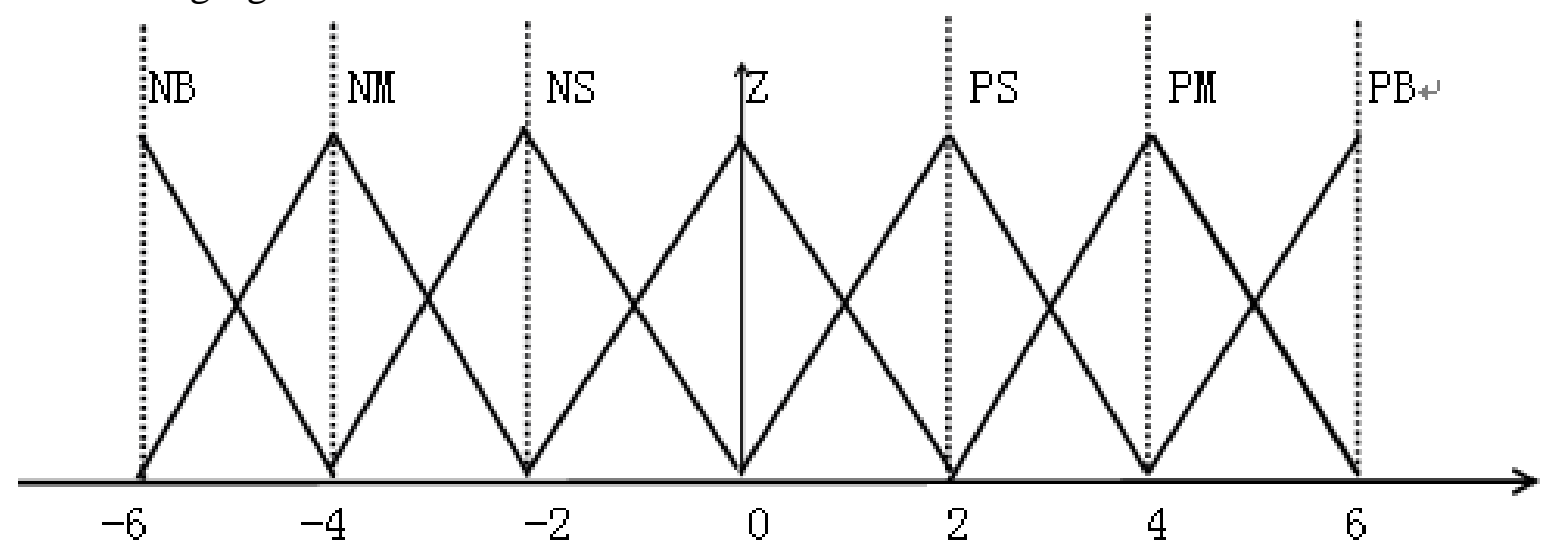

Fig. 3 Membership function graph

Assume the accurate quantity $\mathrm{x}$ (the actual variation range of $\mathrm{x}$ is $[\mathrm{a}, \mathrm{b}])$. The accurate quantity of $[a, b]$ interval is converted into the variable quantity y within the interval $[-6,6]$ in the field of each membership function, and the conversion formula is $\mathrm{y}=12 /(b-a)(\mathrm{x}-(\mathrm{a}+\mathrm{b}) / 2)$ If the value of $\mathrm{y}$ calculated via the above formula is not an integer, it can be treated as an integer nearest to y. CPU will decide the fuzzy set by searching the form of fuzzy rule. This fuzzy set represents fuzziness of accurate quantity $\mathrm{x}$.

Fuzzy control rule set contains a group of fuzzy control rules expressed with fuzzy condition statement, and the fuzzy condition statement of two-input three-output fuzzy control rule of this system is If $\mathrm{E}$ and $\mathrm{EC}$ then $\mathrm{K}_{\mathrm{P}}$ and $\mathrm{K}_{\mathrm{I}}$ and $\mathrm{K}_{\mathrm{D}}$.E means the fuzzy set of the input deviation variable e; EC refers to the fuzzy set of the deviation change rate; $K_{m}(m=P, I, D)$ indicates the fuzzy set of the output variable.[5]

According to self-tuning idea and fuzzy control rule, the following fuzzy control rule state table of $\mathrm{Km}(\mathrm{m}=\mathrm{P}, \mathrm{I}, \mathrm{D})$ parameter is designed. In PID controller, selection of $\mathrm{K}_{\mathrm{P}}$ value depends on the system response speed.Integral control $\mathrm{K}_{\mathrm{I}}$ is mainly utilized to eliminate steady state error of the system .[6]The function of derivative $K_{D}$ link coefficient is to change the dynamic characteristics of the system. The control rule of $\mathrm{K}_{\mathrm{m}}(\mathrm{m}=\mathrm{P}, \mathrm{I}, \mathrm{D})$ is shown in Table 1. 
Table $1 \mathrm{Km}$ fuzzy rule table

\begin{tabular}{|c|c|c|c|c|c|c|c|}
\hline $\begin{array}{c}\mathrm{EC} \\
\operatorname{Km}(\mathrm{P}, \\
\mathrm{I}, \mathrm{D}) \\
\mathrm{E}\end{array}$ & NB & NM & NS & Z & PS & PM & $\mathrm{PB}$ \\
\hline NB & $\mathrm{PB} / \mathrm{NB} / \mathrm{PS}$ & $\mathrm{PB} / \mathrm{NB} / \mathrm{NS}$ & $\mathrm{PM} / \mathrm{NM} / \mathrm{NB}$ & $\mathrm{PM} / \mathrm{NM} / \mathrm{NB}$ & $\mathrm{PS} / \mathrm{NS} / \mathrm{NB}$ & Z/NS/NM & $\mathrm{NS} / \mathrm{Z} / \mathrm{PS}$ \\
\hline NM & $\mathrm{PB} / \mathrm{NB} / \mathrm{PS}$ & $\mathrm{PB} / \mathrm{NB} / \mathrm{NS}$ & $\mathrm{PM} / \mathrm{NB} / \mathrm{NB}$ & PS/NS/NM & PS/NS/NM & Z/Z/NS & $\mathrm{NS} / \mathrm{Z} / \mathrm{Z}$ \\
\hline NS & $\mathrm{PM} / \mathrm{NM} / \mathrm{Z}$ & $\mathrm{PM} / \mathrm{NM} / \mathrm{NS}$ & $\mathrm{PM} / \mathrm{NS} / \mathrm{NM}$ & $\mathrm{PS} / \mathrm{NS} / \mathrm{NM}$ & $\mathrm{Z} / \mathrm{NS} / \mathrm{NS}$ & $\mathrm{NS} / \mathrm{Z} / \mathrm{NS}$ & $\mathrm{NS} / \mathrm{Z} / \mathrm{Z}$ \\
\hline Z & $\mathrm{PM} / \mathrm{NM} / \mathrm{Z}$ & $\mathrm{PM} / \mathrm{NM} / \mathrm{NS}$ & $\mathrm{PS} / \mathrm{NS} / \mathrm{NS}$ & Z/Z/NS & NS/PS/NS & NM/PM/NS & $\mathrm{NM} / \mathrm{PM} / \mathrm{Z}$ \\
\hline PS & $\mathrm{PS} / \mathrm{NM} / \mathrm{Z}$ & $\mathrm{PS} / \mathrm{NS} / \mathrm{Z}$ & $\mathrm{Z} / \mathrm{Z} / \mathrm{Z}$ & $\mathrm{NS} / \mathrm{Z} / \mathrm{Z}$ & $\mathrm{NS} / \mathrm{PS} / \mathrm{Z}$ & $\mathrm{NM} / \mathrm{PM} / \mathrm{Z}$ & $\mathrm{NB} / \mathrm{PB} / \mathrm{Z}$ \\
\hline PM & $\mathrm{PS} / \mathrm{Z} / \mathrm{PB}$ & Z/Z/NS & NS/PS/PS & NM/PS/PS & NM/PM/PS & $\mathrm{NB} / \mathrm{PB} / \mathrm{PS}$ & $\mathrm{NB} / \mathrm{PB} / \mathrm{PB}$ \\
\hline $\mathrm{PB}$ & $\mathrm{Z} / \mathrm{Z} / \mathrm{PB}$ & Z/Z/PM & NM/PS/PM & NM/PM/PM & NM/PM/PS & $\mathrm{NB} / \mathrm{PB} / \mathrm{PS}$ & $\mathrm{NB} / \mathrm{PB} / \mathrm{PB}$ \\
\hline
\end{tabular}

Finally, fuzzy control system will transfer an accurate quantity to the actuating mechanism. Therefore, the fuzzy quantity should be converted into clear quantity and weighted average method will be adopted here. We gained $X_{o}=\sum_{i=1}^{n}(X i * u i) / \sum_{i=1}^{n} u i$, the average value $X_{o}$ is the judgment result of fuzzy set gained via weighted average method.So the output control voltage signal of fuzzy is $u(n)=K_{p} e(n)+K_{I} \sum e(n)+K_{D}[e(n)-e(\mathrm{n}-1)]$. In the formula, $u(n)$ refers to the output voltage signal of fuzzy at the sampling time $n ; e(n)$ indicates the error signal at the sampling time $n$.The final output signal according to the actual variation range,linear conversion is adopted.[7]

Simulation study.Parameters in fuzzy - PID algorithm are simulated by utilizing MATLAB software, and setting of parameters is shown:the input angle is $5^{\circ}$ (the actual range $0-1.47^{\circ}$ ), the variation range of error change rate is -10--10.the initial value of $K_{P}$ is 0.2 (the actual range $0.17-0.21$ ), the initial value of $K_{I}$ is 0.04 (the actual range $0-0.07$ ), the initial value of $K_{D}$ is 0.01 (the actual range 0-0.06),the second-order system model $K_{m}$ is 2,the $T_{m}$ is 0.4 . The following figures show the simulation results of MATLAB. When the input signal is the step signal of $5^{\circ}$, the output quantity response curve of system realized by fuzzy PID algorithm is as follows.

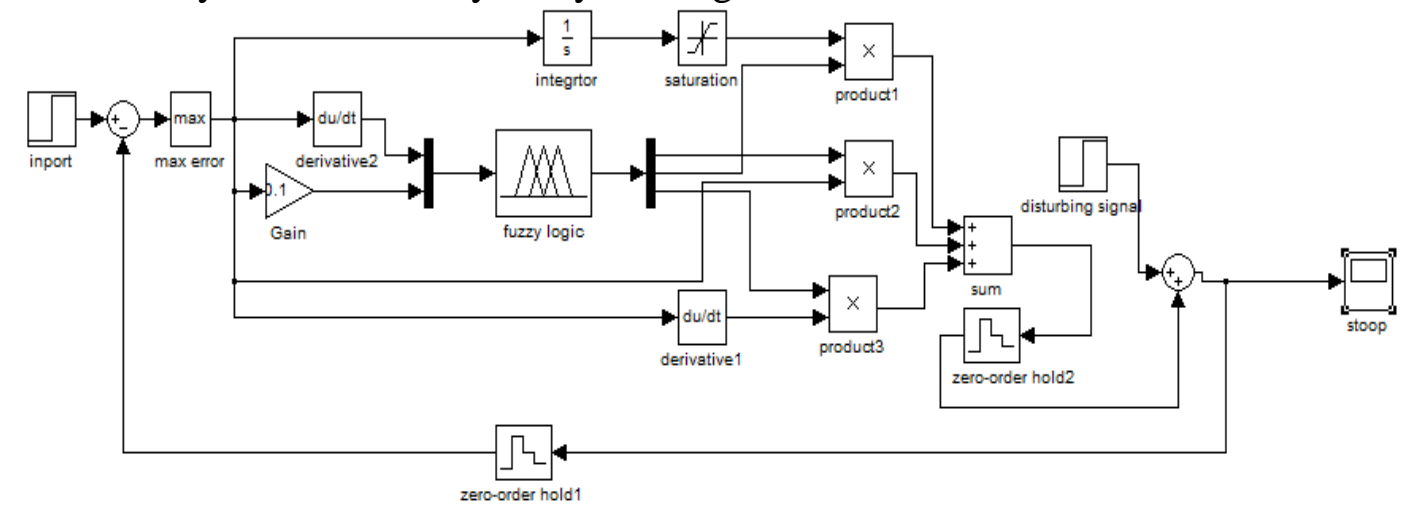

Fig.4 SIMULINK simulation block diagram of fuzzy PID controller

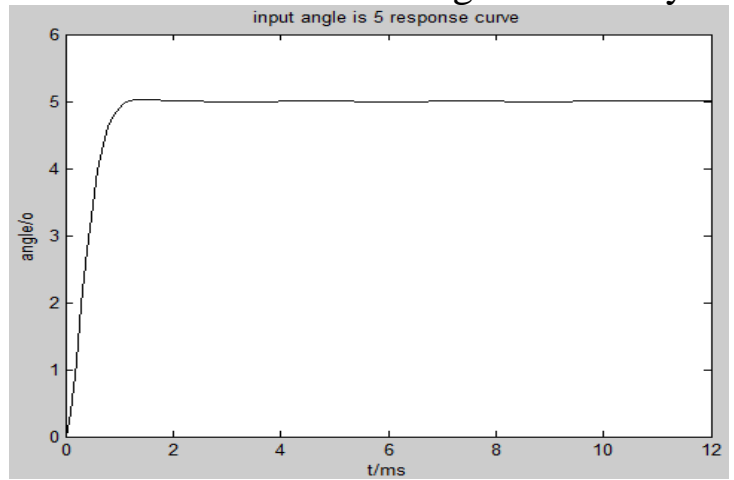

Fig. 5.5 Simulation response curve of fuzzy PID controller when the input angle is $5^{\circ}$ 


\section{Summary}

This paper conducts systematic analysis and designs for the deflection angle controller of ship steering engine and the control link. By establishing mathematical model and interference model of various links of the control system, theoretical foundation of system establishment is provided. Besides, fuzzy - PID algorithm applied at this time is proposed by directing at logical algorithm. It is analyzed through simulation, and a good effect is gained. The simulation results intuitionally verify the feasibility of fuzzy - PID algorithm for deflection angle control of ship steering engine, and prove its correctness. Therefore, reference is provided for controller design at this time.

\section{Acknowledgments}

The paper is supported by WHUT National Undergraduate Training Programs for Innovation and Entrepreneurship.

\section{References}

[1]Baogang $\mathrm{Hu}$, Hao Ying,Review of Fuzzy PID Control Techniques and Some Important Issues,Acat Automatica Sinica,2001, 27(4).

[2]S. Jagannathan, M.W. Vandegrift, F.L. Lewis,Adaptive Fuzzy Logic Control Of Discrete-time Dynamical Sstems,Automatica, 1999, Vol.36 (2), pp.229-24.

[3]Wei Fu, Bing Zhen,Electrostatic Maneuvering Target Tracking Based On Fuzzy Interacting Multiple Model Particle Filter,Acta Armamentarii,2014, 35(1).

[4]Wei Wang, JingTao Zhang, TianYou Chai,A Surcey Of Advanced PID Paramater Tuning Methods,Acat Automatica Sinica,2000, 26(3).

[5]JinLong Zhang,Hui Xu,JingNan Liu, PID Control Based On Fuzzy Neural Network For Precision Angular Alignment,Chinese Journal of Scientific Instrument,2012, 33(3).

[6]ZongXia Jiao, Qing Hua, XiaoDong Wang,Estimation For Performance Of Load Simulator,Chinese Journal Of Mechanical Engineering,2002, 38(11).

[7]HuaShu Peng,HuaDe Li,Zhon Su,Sliding Mode Variable Structure Control Of Electric Steering Engine With Uncertain Parameters, Electric Machines And Control,2009, 13(1). 